\title{
The feasibility of using photovoltaic panels to illuminate the entryway to an apartment building
}

\author{
Liudmila Sumarokova ${ }^{1}$, Alena Surovezhko, ${ }^{1, *}$ \\ ${ }^{1}$ National Research Tomsk Polytechnic University, 634050 Tomsk, Russia
}

\begin{abstract}
The article considers the possibility of using an LED lighting system with a power source from solar modules in the climatic conditions of Siberia. The technical possibility of implementing an autonomous house lighting system is shown for example in the lighting of a residential fivestory building located in Tomsk. The choice and justification of the necessary electrical equipment for solar panels was made. Calculations have been made for the energy consumption of the existing lighting system and a system with LED light sources from photovoltaic panels. The payback period of the project is determined. On the example of an autonomous system of interior lighting of an apartment building, conclusions were made about the feasibility and efficiency of using photovoltaic panels in the climatic conditions of Tomsk region.
\end{abstract}

The purpose of this paper is to evaluate the possibility of using photovoltaic panels as a power source for LED lighting fixtures in common areas in Siberia. As an object for the designing of the LED lighting system was chosen a residential five-story house located at the address: Tomsk city, Lenin Avenue, 255 house. $40 \mathrm{~W}$ filament lamps (FL) are used to illuminate the approach in this house, 11 lamps are in each entrance.

For the selection lighting system of common areas, monthly electricity consumption was calculated; the calculation results are given in Table 1 . The data were obtained based on the average duration of day and night time during each month for 2015, the work of LED lighting fixtures with motion sensors and photosensors was taken into account, and also 1.5 minutes after switching on were included in working time. Three persons live in one apartment; there are 4 apartments on the floor, 5 floors, 4 entrances. On the average, it was also taken into account that every person who lives there goes out and goes in 4 times per day. The duration of cloudy and overcast weather was not taken into account in the calculations. Information of the duration of the day in each month was taken from the site pogodavtomske.ru.

\footnotetext{
* Corresponding author: aos16@tpu.ru
} 
Table 1 - Monthly consumption of electricity by the lighting system in common areas on the base of LED lamps ( $5 \mathrm{~W}$ ) of a residential five-story house at the address: Tomsk city, Lenin Avenue, 255 house.

\begin{tabular}{|l|l|l|l|l|l|l|l|l|l|l|l|l|}
\hline Month & 1 & 2 & 3 & 4 & 5 & 6 & 7 & 8 & 9 & 10 & 11 & 12 \\
\hline $\mathrm{kW} \cdot \mathrm{h}$ & 28.3 & 23.2 & 22.5 & 18.6 & 16.3 & 14.2 & 15.4 & 17.5 & 21.3 & 23.8 & 27.5 & 29.1 \\
\hline
\end{tabular}

Based on the calculated data, it can be concluded that the longest lighting of the entrances works in December and January, because the duration of the day is short, and the weather is mostly cloudy, which also shortens the duration of daytime. Changing FL to an LED lighting system with different sensors can reduce the power consumption in more than 30 times. The service life of LED lamps is in 60 times higher than FL. This means that the working hours of the LEDs is more than 60000 hours, if interpret into real time then such LED lights will last more than 10 years [1].

To estimate the possibility of obtaining electricity from photovoltaic panels, calculations were made according to monthly and annual values of solar radiation, taking into account the different arrangement of the panels: horizontal, vertical and at an angle of $45^{\circ}$ degrees. The results of the calculations are shown in Table 2.

Table 2 - Average monthly and total annual insolation for different orientations of photovoltaic panels, $\mathrm{kW} \cdot \mathrm{h} / \mathrm{m}^{2}$.

\begin{tabular}{|c|c|c|c|c|c|c|c|}
\hline \multirow{2}{*}{ Orientation } & \multicolumn{7}{|c|}{ Month } \\
\cline { 2 - 8 } & 1 & 2 & 3 & 4 & 5 & 6 & 7 \\
\hline Horizontal & 20.3 & 45.4 & 104.5 & 108.3 & 111 & 115.8 & 217.7 \\
\hline $45^{\circ}$ & 27.5 & 61.4 & 141.4 & 146.6 & 150.2 & 156.7 & 294.6 \\
\hline Vertical & 65.3 & 114.1 & 147.7 & 98.8 & 70.1 & 67.1 & 82.3 \\
\hline Orientation & \multicolumn{7}{|c|}{ Month } \\
\cline { 2 - 8 } & 8 & 9 & 10 & 11 & 12 & Year \\
\hline Horizontal & 110 & 92.3 & 75.2 & 57.7 & 15.8 & 1058.2 \\
\hline $45^{\circ}$ & 148.9 & 124.9 & 101.8 & 78.1 & 21.4 & 1453.4 \\
\hline Vertical & 83.5 & 98.5 & 130.2 & 149.1 & 66.5 & 1173.1 \\
\hline
\end{tabular}

Having investigated solar insolation in Tomsk, it can be concluded that it is more rational to use solar energy by installing panels in vertical position (Figure 1). This will give the greatest energy output in the winter, because the maximum load on lighting is in the winter. Panels are recommended to install on the south wall of the residential building, because this is more simple and less expensive installation version.

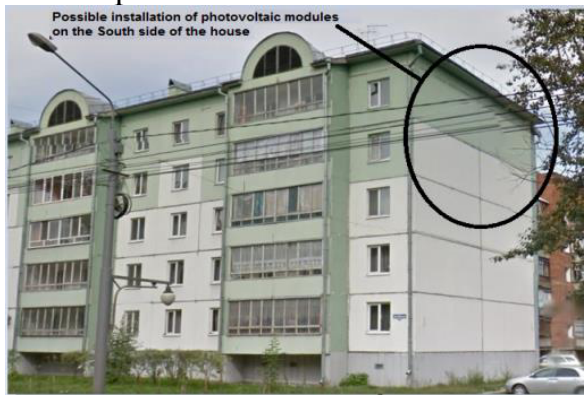

Fig. 1. Place of panels installation on the apartment house.

Solar power plant and uninterrupted power supply (UPS) will be used to power the LED lamps. The solar power plant (SPP) will be the main source of power [2]. There is no device for converting electrical energy such as an inverter in this lighting system with power from SPP. This reduces the cost of such lighting system in general. The main components of SPP: 
1) A solar panel;

2) Electrical battery;

3) Charge Controller EB;

4) LED lighting fixtures (load).

The structural scheme of a solar power plant is shown in Figure 2. The choice of this system is due to the fact that there are few sunny days in Tomsk especially in winter because of large cloudiness and precipitation. This affects the generation of electricity, because the photo panels will not work at full capacity in such days. Therefore, the system needs emergency power source, which have to replace the solar panels (SP) for a certain period of time in order to avoid underproduction of electricity. In the event if the photo panels do not cover the required load, and the battery is discharged, the load will be transfered to the 2nd power source (backup) - a switching power supply that will be connected to the supply [3]. The PSU will always be operational.

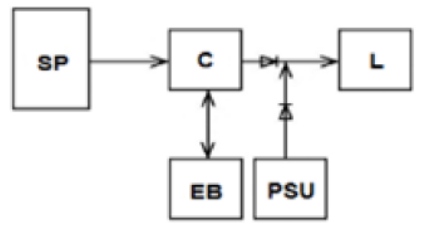

Fig. 2. Block diagram of solar power plant: SP - solar panels, EB - electrical batteries, C - charge controller EB, L - load, PSU - static power supply unit (emergency power source).

Electric power generation as applied to the conditions of the investigated object, as well as electricity consumption by LED lights are shown in the graph of Figure 3.

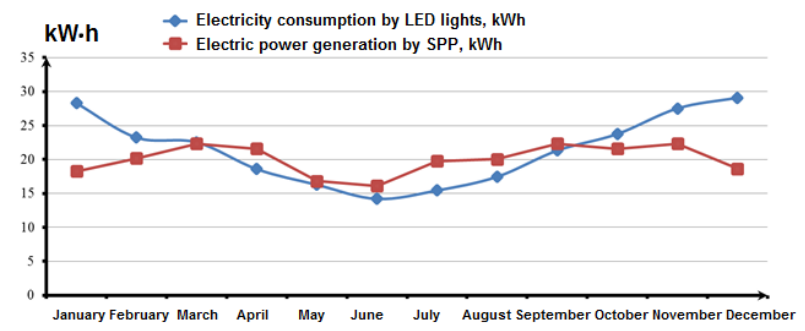

Fig. 3. Comparison of power consumption and power generation.

It can be concluded according to Figure 3, that the equipment will be able to generate enough energy to cover the load from March to September, and the rest of the time: from October to February the remaining underproduction of electricity will be covered with the PSU.

Such development may be well realized, because the payback of the project will be almost 8 years, which proves real and profitable usage of SPP for lighting common areas in Tomsk.

\section{References}

1. S.N. Udalov, Renewable energy sources: Textbook (Publishing House of the National Technical University, Novosibirsk, 2007)

2. L.P. Sumarokova, Naukovedenie 8(6), 11 (2016)

3. M.A. Surkov, Naukovedenie 8(4), 13 (2016) 